\title{
Outdoor Universal Thermal Comfort Index Climatology for Alaska
}

\author{
Nicole Mölders \\ Geophysical Institute, Department of Atmospheric Sciences, College of Natural Science and Mathematics, \\ University of Alaska Fairbanks, Fairbanks, USA \\ Email: cmoelders@alaska.edu
}

How to cite this paper: Mölders, N. (2019) Outdoor Universal Thermal Comfort Index Climatology for Alaska. Atmospheric and Climate Sciences, 9, 558-582.

https://doi.org/10.4236/acs.2019.94036

Received: September 5, 2019

Accepted: October 13, 2019

Published: October 16, 2019

Copyright (c) 2019 by author(s) and Scientific Research Publishing Inc. This work is licensed under the Creative Commons Attribution International License (CC BY 4.0).

http://creativecommons.org/licenses/by/4.0/

\begin{abstract}
Data from 456 surface meteorological sites in Alaska, eastern Russia and northwest Canada for 1979-2017 were used to model hourly universal thermal comfort indices (UTCIs) under consideration of Alaska-appropriate clothing. The results served to determine a high-resolution climatology of thermal comfort levels for Alaska at various temporal and spatial scales as well as the frequency of thermal stress levels. On 1979-2017 average, various degrees of cold stress occurred with highest percentage on the Alaska West Coast and along the Arctic Ocean. In the continental and Inside Passage region, no thermal stress had the highest percentage of occurrence. In Interior Alaska, both strong heat and extreme cold stress occurred occasionally. At most sites and in all Alaska Köppen-Geiger bio-climate regions, the absolute range between monthly means of daily minimum and maximum UTCIs was larger than that of monthly means of daily minimum and maximum air temperatures. Major contributors to thermal discomfort (shortwave radiation, air temperature, moisture, wind speed) varied among bio-climate regions and in the diurnal and annual courses.
\end{abstract}

\section{Keywords}

UTCI, Universal Thermal Comfort Index, Thermal Stress in Alaska, Bio-Climate of Alaska, Thermal Stress Climatology of Alaska

\section{Introduction}

In recent years, the number of people exposed to the extreme elements of Alaska's weather has increased due to population growth (almost 23\% between 1994 and 2018 [1]), last-chance tourism, new activities for oil and gas exploration/production, and mining as well as increased Arctic shipping [2] [3]. Like for 
high levels of heat stress, extended exposure to extreme levels of cold stress can impact human health, reduce the efficiency of performed activities, lead to frost bite, hypothermia or even death when the exposure impairs thermoregulation [4] [5] [6] [7] [8]. Cold stress is a significant risk factor among patients, particularly women with cardiovascular diseases [9]. Unlike heat waves, during which mortality raises for several days, cold spells may increase levels of mortality for several weeks [5]. Thus, as more people visit, work and/or live in Alaska and its off-shore areas, adequate public health system and urban planning require assessment of the outdoor thermal environmental conditions in form of climatology and frequency of occurrence at high spatial resolution.

Typically, negative influences of thermal stress on human health and performance are expressed in terms of thermal stress indices. Various thermal stress indices have been developed. They differ with respect to their input data (airflow velocity, temperature, humidity, solar radiation, etc.), rational, concepts and location [10] [11] [12] [13]. For instance, most thermal stress indices assume a standard outfit (light shirt, slacks). Some indices are valid only for air temperatures above (e.g. heat index, humidex for $T_{a}>20^{\circ} \mathrm{C}$ ) or below a threshold (e.g. $T_{a}$ $\leq 0^{\circ} \mathrm{C}$; wind chill index, wind chill equivalent temperature index). Analytical indices base on the principles of thermal heat exchange between the human body and its environment; empirical indices base on human response or comfort to various environmental factors; direct indices rely on measurements like the apparent $\left(A T=T_{a}+0.33 \times v_{a}-0.7 \times v_{a}-4\right.$, where $v_{a}$ is wind speed), operative or the most commonly used Wet-Bulb Globe Temperature $\left(W B G T=0.567 \times T_{a}+\right.$ $\left.0.393 \times v_{a}+3.94\right)$. The Standard Effective Temperature (SET) considers physiological parameters (skin temperature and wetness). The Effective Temperature (ET) [14] [15] and Physiological Equivalent Temperature (PET) were developed for indoor activity. The Mediterranean Outdoor Comfort Index (MOCI), for example, was optimized for the Cs climates [16]. The PET is based on energy balance considerations and is the output of the Munich Energy Balance Model for Individuals (MEMI). Some indices originally developed for indoor climate (e.g. SET) were adapted later to outdoor environments (OUTSET) by adding the impacts of shortwave radiation [17] [18].

In studies on weather impacts on health, the mean radiant temperature $T_{m r t}$ defined as the "uniform temperature of an imaginary enclosure in which the radiant heat transfer from the human body equals the radiant heat transfer in the actual non-uniform enclosure" [19] is a better measure than ambient air temperature [20]. $T_{m r t}$ depends, among other things, on shortwave and long-wave radiation fluxes from all sides, body posture (sitting, standing, etc.), the absorption of shortwave and long-wave radiation by the human body, and wind speed. Thus, it represents the combined effects of radiant and convective heat gains/ losses for the human energy balance in the outdoors. Studies in Freiburg, Germany, for instance, revealed that $T_{m r t}$ can differ up to $37^{\circ} \mathrm{C}$ between shaded and sunlit areas, whereas air temperature, $T_{a}$ differs only $1^{\circ} \mathrm{C}-2^{\circ} \mathrm{C}$ between the two. The Global Outdoor Comfort Index (GOCI), for instance, uses empirical rela- 
tions depending on $T_{m r r} T_{a}$, relative humidity, $V_{a}$, latitude, mean annual temperature, mean temperatures of the hottest and coldest months [21].

Only few studies on thermal comfort in high latitudes exist. A study in Göteborg, Sweden (Dfb climate), for instance, showed that $T_{m r t}$ can be much lower than $T_{a}$ on extremely cold days with almost no shortwave radiation reaching the surface [22]. A study in Göteborg $(57.70 \mathrm{~N}, 11.94 \mathrm{E}$ Dfb), Luleå $(65.54 \mathrm{~N}, 22.11 \mathrm{E}$ $\mathrm{Dfc})$ and Stockholm $(59.35 \mathrm{~N}, 18.06 \mathrm{E} \mathrm{Dfb})$ found that during clear sky conditions, the highest and lowest $T_{m r t}$ occurred near sunlit walls and in shaded areas, respectively; spatial variation decreased with increasing cloudiness [22]. Under cloudy conditions, highest $T_{m r t}$ occurred in open areas due to high shortwave diffuse radiation from the sky vault. While in winter, $T_{m r t}$ strongly differed with latitude, no such sensitivity occurred in summer [22]. A summer study on the thermal comfort in Apatity $(67.567 \mathrm{~N}, 33.4 \mathrm{E})$ in the Murmansk region of Russia north of the Arctic Circle found significant spatial variation of PET during contrast weather conditions [23].

Various studies showed that cold stress caused different responses depending on the bio-climate region. Cold spells, for instance, can cause notable and often significant increases in mortality in elderly people (65 years or older) from cardiovascular causes, especially strokes, coronary heart disease events, and respiratory causes in subtropical Cfa [7], in mid-latitude $\mathrm{Cfb}$ [4], and high latitude Dfb climate [6]. In regions with warm winters, mortality from cardiovascular diseases (CVD) increases with a given temperature decrease; in Ireland (Cfb climate), the CVD mortality rate is $45 \%$ higher in December than August, while it amounts to $28 \%$ in the much colder winters of Norway [5] ( $46 \%$ in Dfc, $\sim 26 \%$ in $\mathrm{Cfb}, \sim 26 \%$ in $\mathrm{Cfc}, \sim 1 \%$ in ET, less than $1 \%$ in Cfc climate).

Alaska still lacks an assessment of human thermal comfort at a regional scale. Weather differs widely over the state depending on the location with respect to the semi-permanent high-pressure systems, major storm tracks, elevation above sea level, distance from the coast and the presence or absence of seasonal sea-ice [27]. Consequently, Alaska falls into several climate regions [24] [28] [29] [30] (e.g. Figure 1). Unfortunately, currently available thermal stress maps like, for instance, from global simulations of various heat-stress metrics within the Community Land Model $\left(1^{\circ} \times 1^{\circ}\right)$ [12] or derived from ERA-Interim (T255 79 $\mathrm{km})$ [31] are too coarse to capture Alaska's complex topographic and environmental and hence thermal comfort conditions.

The goals of this study were to fill this gap with a climatology and to identify regions of huge thermal hazards as well as the frequency thereof. To achieve this goal, I used near-surface meteorological observations between 1979 and 2017 (both included) to assess the thermal comfort using the Universal Thermal Comfort Index (UTCI) model [32] [33].

The UTCI was chosen for the following reasons: The UTCI bases on the well evaluated [34] advanced multi-node human thermoregulation model [35]. The UTCI proved itself to be able to represent bioclimatic conditions in terms of human strain under a wide range of climatic outdoor conditions [10]. The 


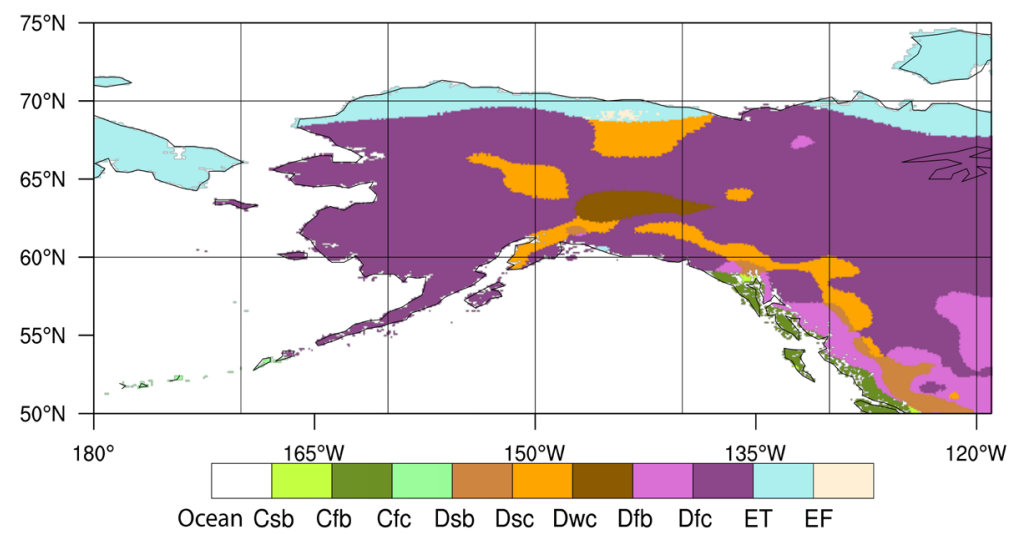

Figure 1. Köppen-Geiger classification for Alaska at $0.5^{\circ} \times 0.5^{\circ}$ resolution as determined for 1951-2000 by [24] based on datasets from the Climatic Research Unit (CRU) [25] and Global Precipitation Climatology Centre (GPCC) [26]. This resolution is between $~ 34.94$ $\mathrm{km}$ (Amatignak 51.2704N, 179.1199W) and $17.82 \mathrm{~km}$ (Nuvuk aka Point Barrow 71.3875N, $156.4811 \mathrm{~W}$ ) in west-east and $\sim 55.5 \mathrm{~km}$ in south-north direction. Except for the area of the three major cities (Anchorage 61.2181N, 149.9003W; Fairbanks 64.8378N, 147.7164W; Juneau $58.3019 \mathrm{~N}, 134.4197 \mathrm{~W}$ ), the mean distance between sites exceeds $34.94 \mathrm{~km}$, i.e. gridded data include interpolated classifications.

model includes an evaluated clothing model [34] [35] [36] that considers human behavior of adapting insulation based on ambient air temperature in the determination of thermal comfort [32] [33] [35] [36]. This means the clothing model permits a realistic description of clothing insulation for Alaska. Furthermore, a comparison using one year of 6 am to 9 pm daily data revealed significant correlations $(\mathrm{P}<0.0001)$ between UTCI and other heat indices (PET, PMV, SET, WBGT), and environmental parameters (e.g. dry temperature); UTCI correlated the strongest with PET $\left(r=0.96 ; r^{2}=92 \%\right)$ followed by WBGT $(r=0.88)$, SET $(r=0.87)$, and dry temperature $(r=0.90)$. Note that PET and SET are based on the body thermal equation, while the thermal perception of WBGT is more similar to that of the UTCI than that of other indices [13]. See [10] and [12] for comparisons of thermal indices.

\section{Experimental Design and Methodology}

\subsection{Data Sources and Data Processing}

Near-surface meteorological data collected at land, well, ship and buoy sites between 1979 and 2017 were downloaded from the archives of the National Centers for Environmental Information (NCEI), National Climatic Data Center (NCDC), United States Geological Survey (USGS), Atmospheric Radiation Measurements (ARM), Water Engineering Research Center (WERC), Bureau of Ocean Energy Management (BOEM) and Western Region Climate Center (WRCC). Hereafter, the 1979-2017 timeframe is referred to as the "period". The resulting combined dataset encompassed 456 sites covering Alaska, Northwestern Canada, and eastern Russia, as well as points in the Beaufort and Chukchi Seas, Bering Sea and northern Gulf of Alaska. For all sites solar radiation at the 
top of the atmosphere (TOA), $R_{s, T O A}^{\downarrow}$ was calculated as a function of latitude, day of the year and time of the day (for equation see e.g. [37]).

Since not all data are from operational weather monitoring, data cover timeframes of varying lengths and at different times during the period. Also some operational sites were moved or closed and new sites were set up during the period. Some sites lacked winter precipitation data or winter data at all. Thus, the available data were considered as a sample within the period following [38] and [27].

Observational data were converted to SI units as needed. Daily accumulated precipitation was calculated from hourly or 6-hourly values when not reported as daily values. Furthermore, except for precipitation some data came at smaller time steps than an hour. These data were averaged to hourly values. Relative humidity served to determine dew-point temperatures and vice versa.

Unfortunately, in many of the datasets, the practice to just leave out hours and/or days without observations was used. However, creating a climatology requires a continuous dataset in time for 1) comparison of data from different sites at the same time, and 2) calculation of daily and monthly means as well as diurnal and annual cycles. Therefore, the data were examined for being in continuous daily order for precipitation and in continuous hourly order for all other quantities. Missing data were marked as such. I discarded corrupt or bad quality data and treated them as missing. No interpolation was made for missing data in the time series.

The dataset gave cloud cover as SKC ( $=0$ octas; clear sky), OBS or NSC $(<1$ octa), FEW (1 - 2 octas), SCT (3 - 4 octas), BKN (5 - 7 octas) and OVC (=8 octas; overcast). Assuming equal likelihood for all octas that belong to the same category, the respective categories' mean was used as representative for the cloudcover percentage, i.e. $0 \%, 6.25 \%, 18.75 \%, 21.875 \%, 68.75 \%$ and $100 \%$, respectively.

For each hour without observations of solar radiation at the surface, $R_{s, s f c}^{\downarrow}$, this quantity was calculated from the incoming solar radiation at the TOA dependent on observed cloud cover, $c$ as

$$
R_{s, s f c}^{\downarrow}=R_{s, T O A}^{\downarrow}\left(1-0.75 \cdot c^{3}\right)
$$

When also no cloud-cover observations existed, cloud cover was estimated from relative humidity as [39]

$$
c=1-\sqrt{\frac{1-r h}{1-r h_{c r i t}}}
$$

where $r h$ is relative humidity as fraction of 1 and $r h_{c r i t}=0.7$ is a critical threshold for cloudiness to occur. Multiplication of $c$ with 100 provides cloud cover in percent.

\subsection{Calculation of the UTCI}

The UTCI combines thermo-physiology and heat exchange theory [32] [33] and 
follows the concept of an equivalent temperature. At any combination of air temperature, wind speed, radiation, and humidity, UTCI is defined as the air temperature, $T_{a}$, in the reference condition, which would elicit the same dynamic physiological response as the actual conditions.

These reference conditions assume a metabolism of $135 \mathrm{~W} \cdot \mathrm{m}^{-2}$, light activity (walking $4 \mathrm{~km} \cdot \mathrm{h}^{-1}$ ), a mean radiant temperature being equal to the $2 \mathrm{~m}$ air temperature, a relative humidity of $50 \%$ for $T_{a} \leq 29^{\circ} \mathrm{C}$ and water vapor pressure $e=$ $20 \mathrm{hPa}$ for $T_{a}>29^{\circ} \mathrm{C}$, and a $10 \mathrm{~m}$ wind speed, $v_{a}$ of $0.5 \mathrm{~m} \cdot \mathrm{s}^{-1}$, which corresponds to about $0.3 \mathrm{~m} \cdot \mathrm{s}^{-1}$ at $1.1 \mathrm{~m}$ above ground level [33]. All other weather conditions are compared to this reference.

As aforementioned, the calculation of the UTCI bases on the well evaluated [34] advanced multi-node human thermoregulation model [35]. This numerical model simulates, among others, the environmental heat exchanges, the heat and mass transfer with the body, thermoregulatory reactions of the central nervous system as well as perceptual responses [33] (Figure 2). The advanced multi-node human thermoregulation model is valid for $-50^{\circ} \mathrm{C} \leq T_{a} \leq 50^{\circ} \mathrm{C},-30^{\circ} \mathrm{C} \leq T_{m r t}$ $T_{a} \leq 70^{\circ} \mathrm{C}, 0.5 \mathrm{~m} \cdot \mathrm{s}^{-1} \leq v_{a} \leq 30.3 \mathrm{~m} \cdot \mathrm{s}^{-1}, 5 \% \leq R H \leq 100 \%$ and water-vapor pressure $e<50 \mathrm{hPa}[33]$.

Thermo-regulation refers to the human's ability to keep the body temperature within certain limits despite of a very different ambient temperature. When body-core temperature and/or skin temperature change, effector responses occur; effector actions depend on weather conditions, clothing and activity [40] [35]. In moderate and warm environments, a person's physiology can maintain body temperature within acceptable limits via thermoregulation; sweating and vasodilation of skin vessels occur to cool the skin by evaporation of sweat [35] [41]. In cold environments, increased convection is the main path to body-heat loss. In response, the thermoregulatory system reduces the peripheral blood flow to decrease skin temperature and to increase the thermal insulation of the skin tissue. Shivering produces heat [40].

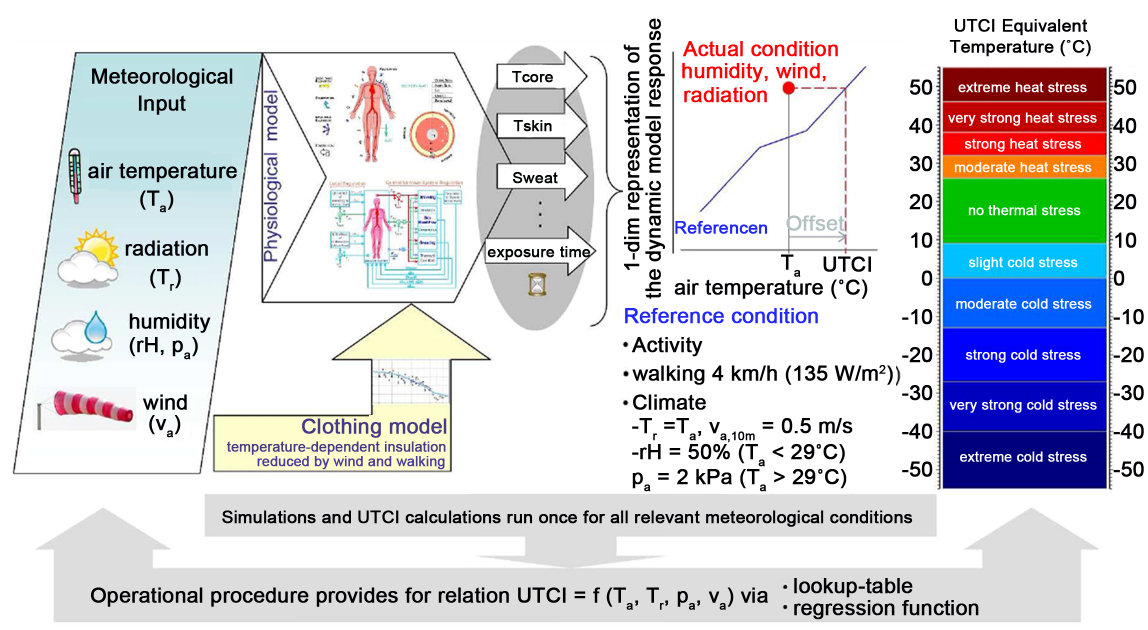

Figure 2. Schematic view of the calculation of the UTCI. From: [33]. 
Adequate clothing, for instance, is a behavioral effector response to thermal conditions [36]. The advanced multi-node human thermoregulation model [35] runs in coupled mode with an adaptive clothing model [36] and predicts the dynamic thermal sensation as an equivalent temperature, the UTCI (Table 1). The model (and hence UTCI) neglects influence of physiological adaptation or acclimation.

The clothing model [36] simulates people's adjusting their clothing to the outside conditions. Insulation changes depending on ambient temperature. At temperatures below $-20^{\circ} \mathrm{C}$, the clothing model assumes special clothing. Clothing insulation values stem from data of actual behavior in the field [36]. A partial clothing approach is used. It accounts for the head and face being covered differently than the torso. It assumes the face to be exposed to the ambient air. Movement of the person and wind reduce thermal and evaporative clothing resistances. At ambient temperature, radiation, relative humidity and wind modulate the physiological response while the clothing remains the same. The incorporated comfort model uses physiological states (skin temperature, core temperature, sweat rate, skin wittedness, etc.) to predict thermal sensation responses to steady state and transient conditions.

The difference between the UTCI value and air temperature, $T_{a}$ depends on the actual air and mean radiant temperature, $T_{m r r}$ wind speed, $V_{a}$ and humidity (water-vapor pressure, $e$ or relative humidity, $R H$ in \%). The model converts the observed $10 \mathrm{~m}$ wind speed to body level assuming a logarithmic wind profile following [42].

The mean radiant temperature is determined following [43]

$$
T_{m r t}=\sqrt[4]{\left(T_{g}+273.15\right)^{4}+\frac{1.06 \times 10^{8} \times v_{a}^{0.58}}{\varepsilon \times D^{0.42}}\left(T_{g}-T_{a}\right)}-273.15
$$

where $T_{g}, V_{a}, T_{a}, \varepsilon$ and $D$ are the globe temperature, wind speed, air temperature, emissivity (0.95) and diameter of the globe. See [11] for a comparison of different methods to determine the mean radiant temperature and their impacts on UTCI (and PET) outdoor comfort levels. The globe temperature was calculated following [44].

Table 1. UTCI equivalent temperatures in terms of thermal stress; values between 18 and $26^{\circ} \mathrm{C}$ fall into the "thermal comfort zone".

\begin{tabular}{cc}
\hline UTCI range $\left({ }^{\circ} \mathrm{C}\right)$ & Thermal stress category \\
\hline $\mathrm{UTCI}>46^{\circ} \mathrm{C}$ & Extreme heat stress \\
$38<\mathrm{UTCI} \leq 46$ & Very strong heat stress \\
$32<\mathrm{UTCI} \leq 38$ & Strong heat stress \\
$26<\mathrm{UTCI} \leq 32$ & Moderate heat stress \\
$9<\mathrm{UTCI} \leq 26$ & No thermal stress \\
$0<\mathrm{UTCI} \leq 9$ & Slight cold stress \\
$-13<\mathrm{UTCI} \leq 0$ & Moderate cold stress \\
$-27<\mathrm{UTCI} \leq-13$ & Strong cold stress \\
$-40 \leq \mathrm{UTCI} \leq-27$ & Very strong cold stress \\
$-40>\mathrm{UTCI}$ & Extreme cold stress \\
\hline
\end{tabular}


The ground surface was assumed as grass until onset of snow cover. Global albedo for shortwave and long-wave radiation was set to 0.2 for dry, snow-free conditions. Surface albedo for grass was set to 0.15 on days with at least one rain event.

A snow cover was assumed when snow depth and/or snowfall were reported. When no snow-depth data existed, a closed snow cover was assumed at latitudes north of $60^{\circ}$ between November and end of March in accord with [29]. Once a snow cover existed, surface albedo was set to 0.55 (fresh snow) and 0.3 (aging snow) for days with at least one and no snow event, respectively.

\subsection{Analysis}

Bio-climate studies typically apply the Köppen-Geiger classification (KGC) [28] [45]. Warm temperate (C), and snow (D) climates are subdivided according to their annual precipitation (second letter) and temperature (third letter) characteristics. The second letters $\mathrm{f}, \mathrm{s}$, and $\mathrm{w}$ indicate fully-humid, dry summers, and dry winters, respectively. The third letters a, b, c, and d indicate hot, warm, cool, and extremely continental summers to describe the impacts of warmth and aridity on vegetation at the regional scale [28] [45]. Unfortunately, many of the surface meteorological sites lacked or had too many missing precipitation data to calculate the KGC at the site scale. For the 370 sites with sufficient precipitation and temperature data year round, the KGC was determined using the available sample of the 1979-2017 period. Since the focus was on the thermal comfort at the actual elevation, in contrast to [28] [45], the observed $2 \mathrm{~m}$ temperature was used, i.e. no reduction to sea-level was made.

For all sites and their available data we determined hourly UTCIs. Frequency of comfort levels, monthly means of daily minimum and maximum UTCIs, 1979-2017 monthly minimum and maximum UTCI at a site and within a bioclimate, daily and monthly means of UTCIs and their higher moments (standard deviation, skewness, kurtosis) [46] as well as the percentage of hours of a given comfort level in the various months were determined from the hourly values.

For each site $i$ with more than one year of observations, the monthly mean over the period for the $f^{\text {th }}$ month $(j=1,12)$ reads

$$
\overline{X_{i, j}}=\frac{1}{m} \sum_{k=1}^{m} X_{i, j, k}
$$

Here $m$ is the number of hourly values in the sample of site $i$ in all $f^{\text {th }}$ months of the period and $X$ stands for $T_{a}$ and UTCI, respectively. Analogously, the higher moments as well as monthly means of daily minimum $\overline{X_{i, j \min }}$ and maximum $\overline{X_{i, j \max }}$ and their higher moments were calculated. At a site, inter-annual variability in monthly means was determined by the variance following [27] [47] [48].

For the various bio-climates in Alaska, the monthly means of thermal comfort and their higher moments were calculated using the hourly UTCIs of sites be- 
longing to the same bio-climate. Thus, the period-spatial mean of the $f^{\text {th }}$ month for a KGC bio-climate reads

$$
\overline{X_{K G C, j}}=\frac{1}{s} \sum_{i=1}^{s} \frac{1}{m(i)} \sum_{k=1}^{m(i)} X_{i, j, k}
$$

Here $m(i)$ is the number of valid data in the sample at the site $i$ during the $f^{\text {th }}$ months in the period and $s$ is the number of sites in the respective KGC bioclimate. Analogously, higher moments, period-spatial monthly means of minimum $\overline{X_{K G C, j \min }}$ and maximum $\overline{X_{K G C, j \max }}$ were determined. Consequently, the variance describes the temporal-spatial variability within a bio-climate. For all sites with at least one year of data, the annual courses of period-monthly means, minima and maxima of both air temperature and UTCI were compared with each other. Furthermore, for each site and KGC bio-climate region the lowest $\left(\mathrm{UTCI}_{\min }\right)$ and highest thermal comfort level $\left(\mathrm{UTCI}_{\max }\right)$ were determined.

\section{Results}

In some continental locations, summer maximum and winter minimum temperatures differed more than $80 \mathrm{~K}$ during the period (not shown). Coastal areas without seasonal sea-ice varied the least between summer and winter temperatures.

The annual course of solar insolation at the TOA differs strongly between North and South Alaska (Figure 3). Radiative forcing governed local weather under calm wind conditions: In winter, the low solar insolation, or even darkness and the snow/ice covered surfaces favored inversion formation via longwave radiation loss; in summer, the high Sun elevation, long daylight times and strong shortwave radiation favored evaporation and eventually convection.

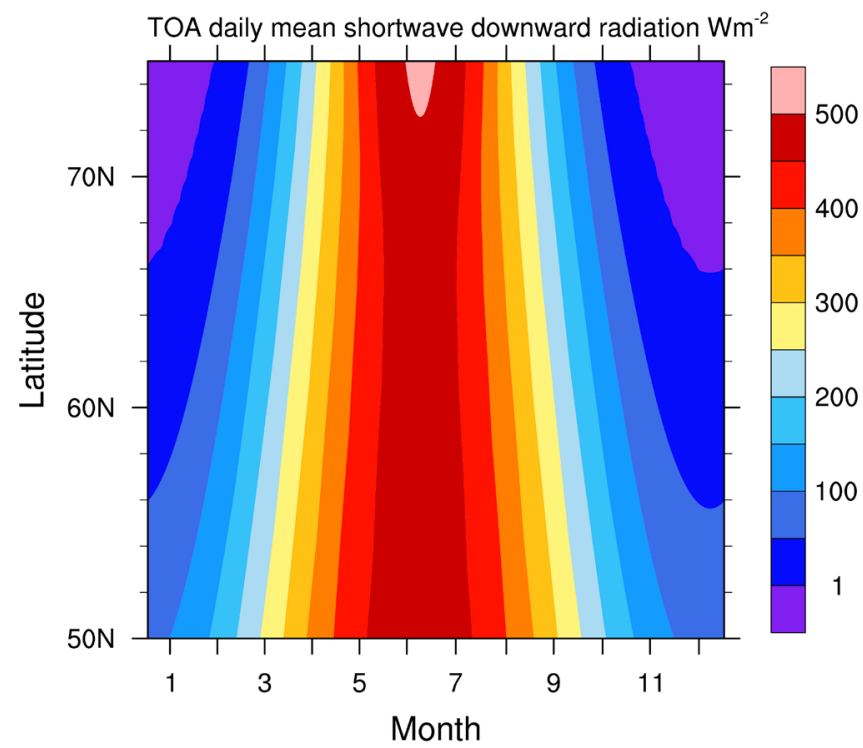

Figure 3. Annual evolution of daily mean incoming solar radiation at the top of the atmosphere (TOA) between $50^{\circ} \mathrm{N}$ and $75^{\circ} \mathrm{N}$. 
Figure 4 exemplarily shows the annual courses of daily means of relative humidity, air temperatures, wind speeds and solar radiation at the surface for three sites: Fairbanks (64.83667N, 147.615W), Kake (56.97389N, 133.66W) and Inigok air field $(70.00361 \mathrm{~N}, 153.0836 \mathrm{~W})$. Incoming solar radiation at the surface, wind speed and relative humidity differed notably among these sites. Available shortwave radiation at the surface impacts UTCI strongly at all sites in winter. Together these different environmental conditions yielded thermal comfort levels that differed from the actual ambient air temperature to various degrees in the annual course.

In Alaska, actual air temperature and UTCI differed at all temporal scales. At the diurnal, monthly and annual-daily course, times existed where $\mathrm{T}_{\mathrm{a}}$ exceeded the UTCI and vice versa (compare e.g. Figure 4, Figure 5). Absolute differences

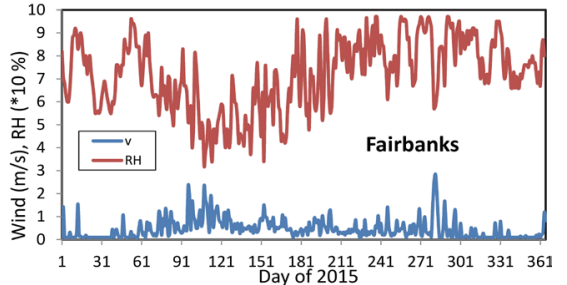

(a)

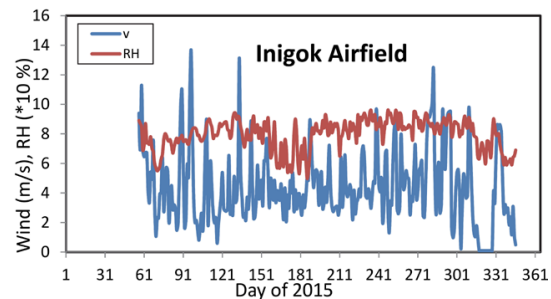

(c)

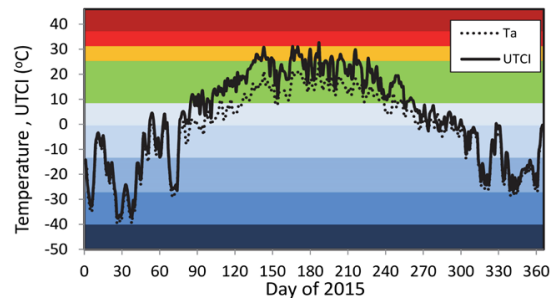

(e)

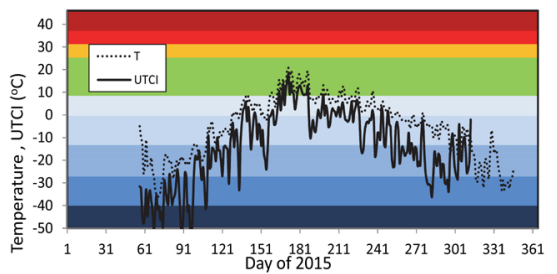

(g)

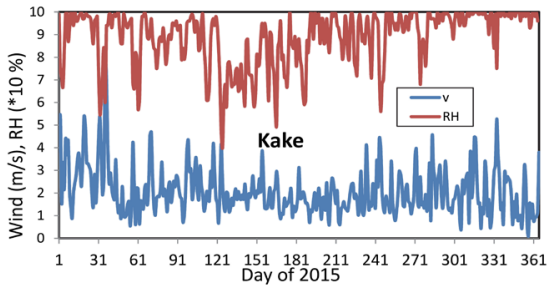

(b)

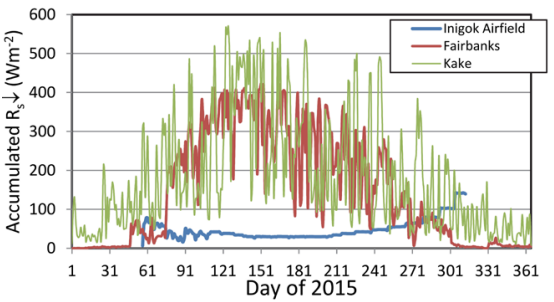

(d)

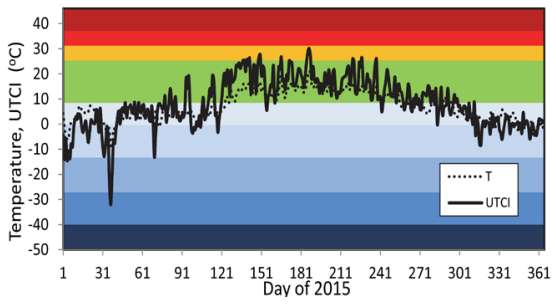

(f)

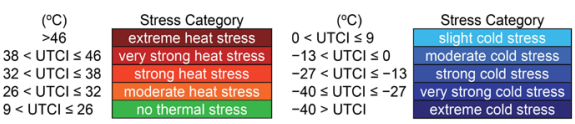

Figure 4. 2015 annual course of daily means of hourly wind speed and relative humidity at (a) Fairbanks; (b) Kake; (c) Inigok air field and (d) daily accumulated solar radiation at the surface at these sites, and annual course of daily means of hourly $2 \mathrm{~m}$ air temperature and UTCI at (e) Fairbanks; (f) Kake; and (g) Inigok air field. 


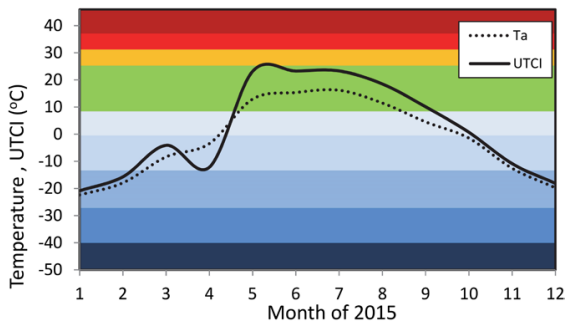

(a)

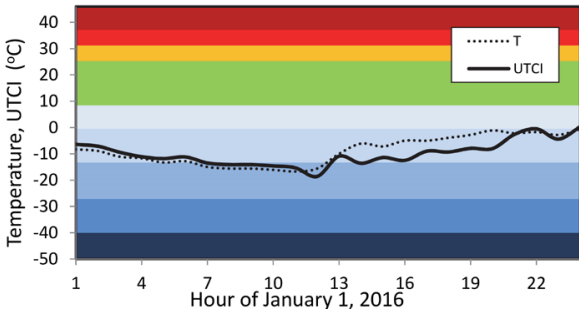

(c)

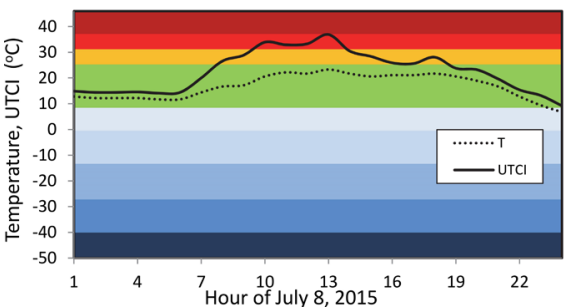

(e)

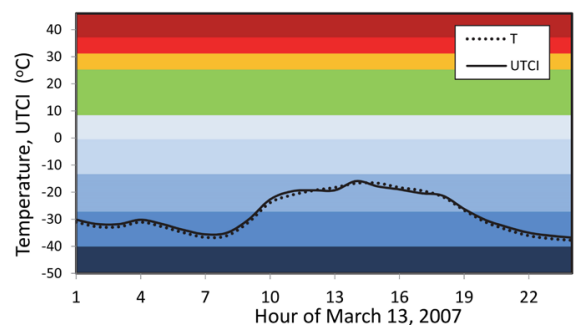

(b)

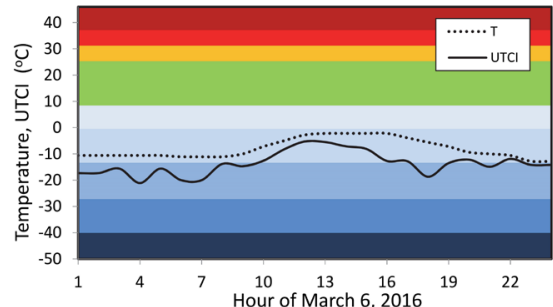

(d)

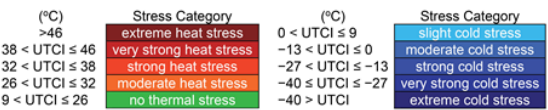

Figure 5. Fairbanks (a) monthly means in 2015, and hourly means in the diurnal course on (b) March 13, 2007; (c) January 1, 2016; (d) March 16, 2016; (e) July 8, 2015.

between actual air temperature and UTCI varied among sites and among bioclimate regions (see Section 3.1).

Obviously, a daily or monthly climatology would exclude hourly or daily extremes (cf. e.g. Figure 6). This means that with only a climatology of monthly or annual means hazardous situations may be underestimated. Therefore, the percentage of hours in each sample for each comfort level was determined as well (see Section 3.3).

\subsection{Thermal Comfort in Various Bio-Climate Regions}

Figure 6 shows examples of the annual course of the 1981-2010 monthly means of precipitation and air temperature for selected Alaska bio-climates. According to [24], the 1951-2000 mean bio-climatological conditions ranged from tundra climate (ET) on the North Slope over subarctic climate in southern Interior Alaska and along the coast of the Bering Sea (Dfc), extremely cold subarctic climate (Dfb) along the northern Panhandle and Interior both at high elevations, subarctic oceanic climate $(\mathrm{Cfc})$ in the Aleutian Chain to temperate oceanic climate $(\mathrm{Cfb})$ on the southern Panhandle (Figure 1). Some pockets of dry-continental subarctic (Dsc), warm-summer Mediterranean-influenced climate (Csb), dry-warm-summer continental climate (Dsb) and ice-cap climate (EF) existed as 


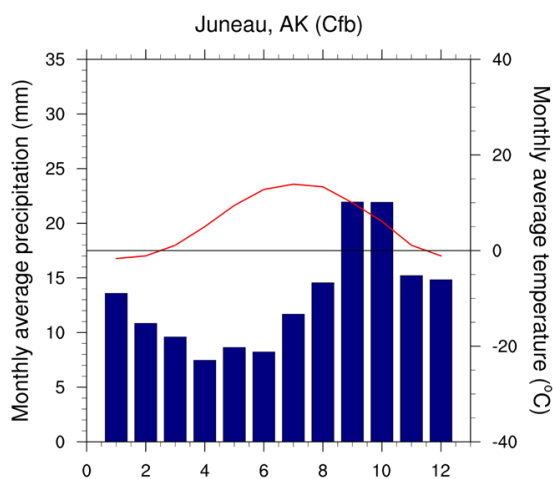

(a)

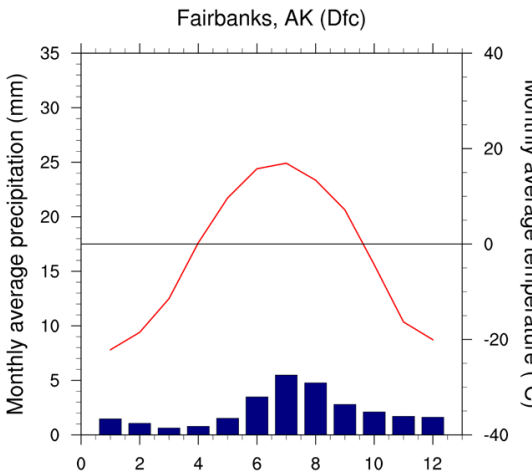

(c)

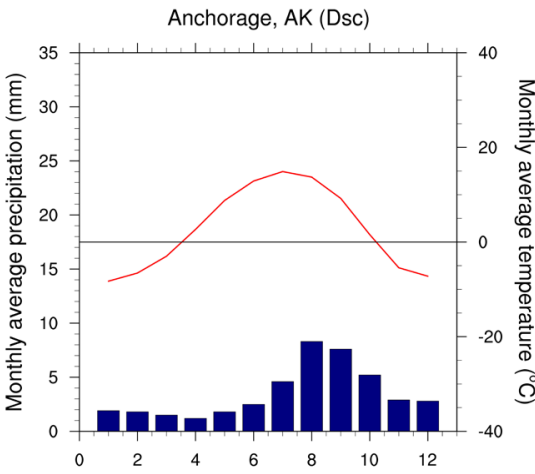

(e)

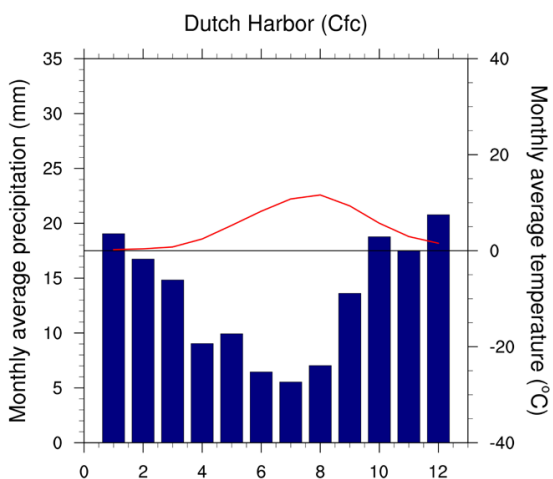

(b)

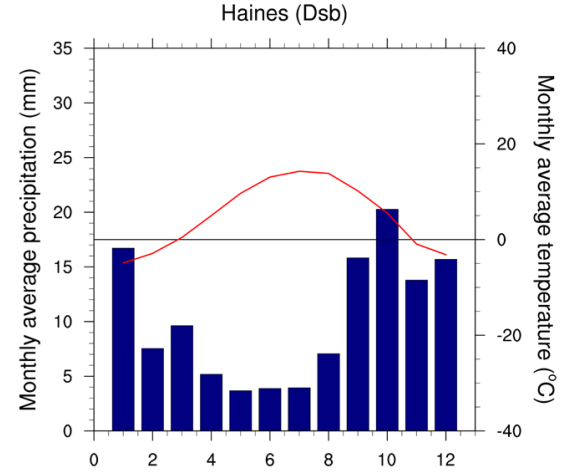

(d)

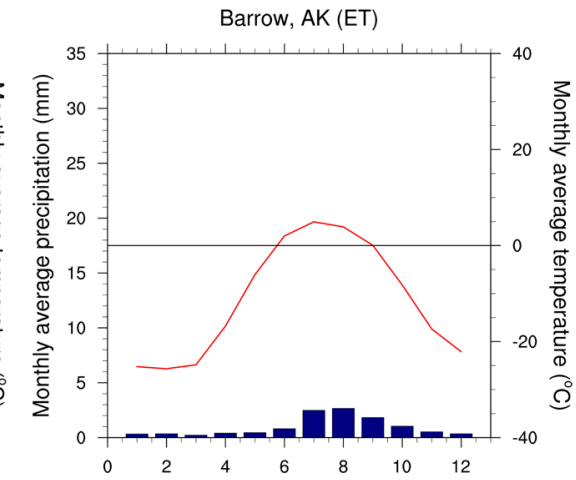

(f)

Figure 6. 1981-2010 climate monthly average precipitation and monthly mean $2 \mathrm{~m}$ air temperature for selected sites in various bio-climate regions.

well. A similar distribution was obtained for 1979-2017 when determining the KGC using for the 370 sites that had sufficient air temperature and precipitation data (therefore not shown).

In this section, the thermal comfort for 1979-2017 is discussed based on the data of these 370 sites. For most sites and all bio-climates, the absolute difference between monthly means of daily maxima of UTCI and air temperatures were typically much larger than those between monthly means of UTCI and air temperatures. (e.g. Figure 7) The same was true for monthly means of daily minima of UTCIs and air temperatures. 


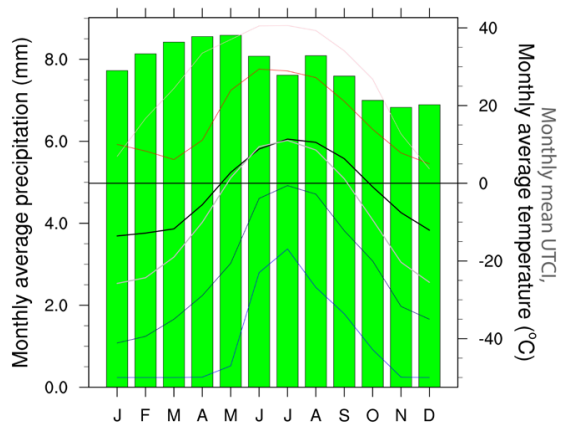

(a)

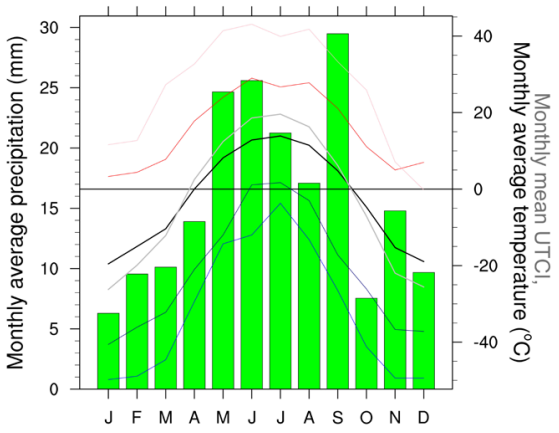

(b)

Figure 7. Annual course of 1979-2017 monthly mean precipitation (green bars), monthly mean $2 \mathrm{~m}$ air temperature (black), monthly mean UTCI (gray), monthly means of minimum (navy) and maximum (red) $2 \mathrm{~m}$ air temperatures and monthly means of minimum (blue) and maximum (pink) UTCI at (a) Nome (64.5111N, 165.44W) and (b) Nabesna Devil Mountain (62.3986N, 142.9950W).

\subsubsection{Marine West Coast Climate ( $\mathrm{Cfc}, \mathrm{Cfb})$}

Along the coast of the Gulf of Alaska, frequent cyclones cause windy, wet conditions [29]. Thus, frigid thermal conditions are often paired with high humidity and/or high wind speeds, which can lead to wind chill. Under windy winter conditions blowing snow may occur as well.

Cfc bio-climate has the same annual precipitation pattern as Cfb bio-climate, but with lower temperature conditions (e.g. Figure 6(a), Figure 6(b)). Overall, in both $\mathrm{Cfb}$ and $\mathrm{Cfc}$ climates, thermal comfort levels encompassed a wider range than actual temperatures. Monthly means of daily minimum UTCI and maximum air temperatures were lower than those of daily minimum air temperature and maximum UTCI, respectively.

Spatially-averaged over all sites with Cfb bio-climate, the period-annual course of monthly mean UTCI spanned $21.8 \mathrm{~K}$. Monthly mean UTCI was highest in July $\left(16.3^{\circ} \mathrm{C} \pm 1.5^{\circ} \mathrm{C}\right)$, lowest in January $\left(-5.4^{\circ} \mathrm{C} \pm 3.2^{\circ} \mathrm{C}\right)$, and below the freezing point from November to March (Figure 8(a)). Monthly mean UTCIs typically exceeded monthly mean temperatures from May to August (Figure 8(b)). The opposite was true from October to March. Together these findings suggest that on average, May to September saw no thermal stress, while moderate thermal stress occurred from November to March. The lowest minimum and highest maximum 1979-2017 UTCI-values were $-12.9^{\circ} \mathrm{C}$ and $18.6^{\circ} \mathrm{C}$, respectively (Table 2).

On period-average over all Cfc sites, the difference between the highest and lowest mean monthly UTCIs in the period-annual course was $25.6 \mathrm{~K}$, i.e. larger than in $\mathrm{Cfb}$ bio-climate. January and July had the lowest $\left(-14.7^{\circ} \mathrm{C}\right)$ and highest monthly mean UTCIs $\left(11.0^{\circ} \mathrm{C}\right)$. On average, at least moderate cold stress occurred from October to April (Figure 8(b)). Monthly mean UTCIs exceeded monthly mean air temperatures from May to August, while the opposite was true from October to March. In January, strong cold stress existed on average, while July monthly means of maximum UTCIs were in the thermal comfort 


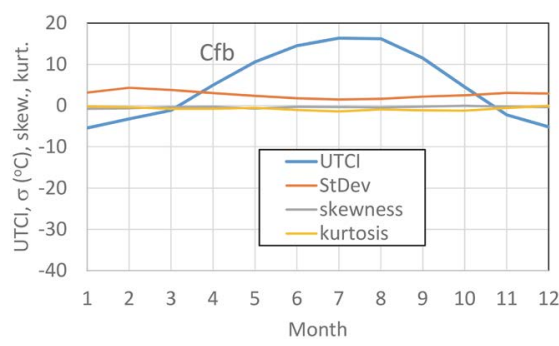

(a)

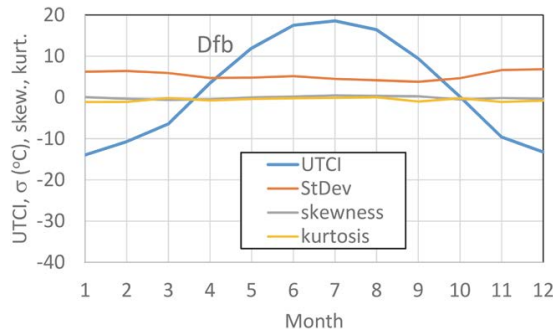

(c)

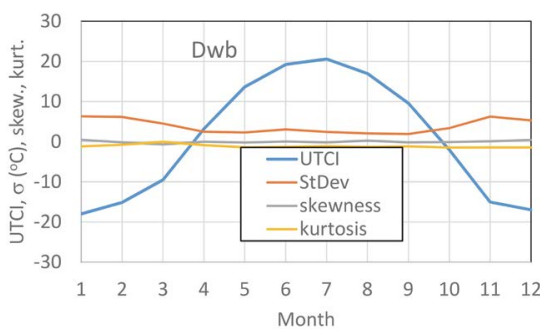

(e)

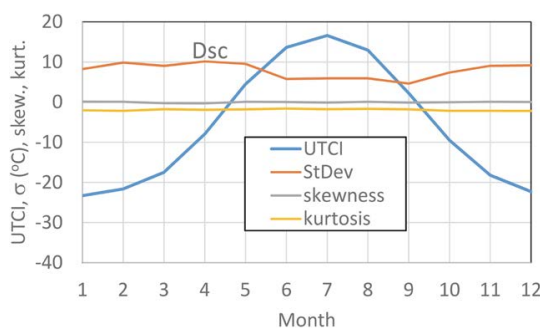

(g)

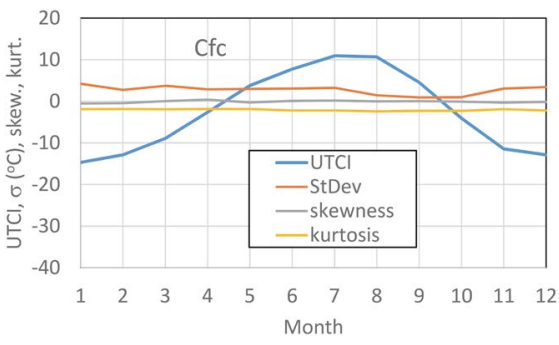

(b)

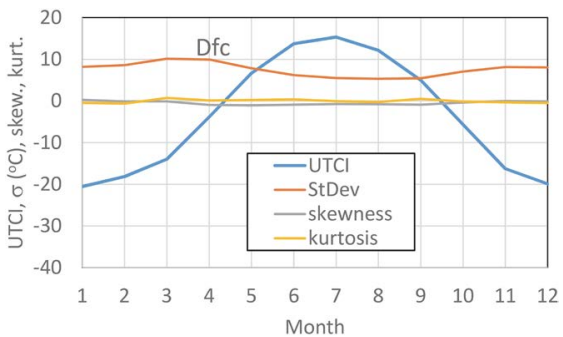

(d)

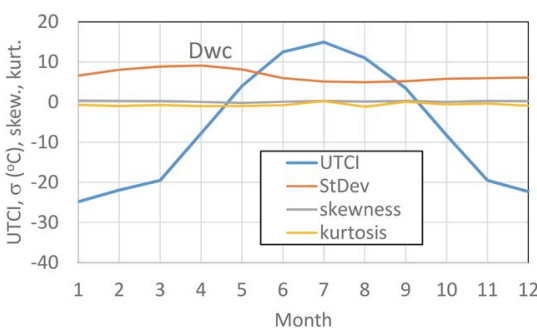

(f)

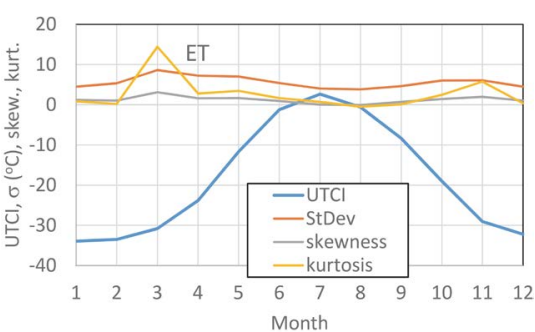

(h)

Figure 8. Bio-climate period-spatial monthly mean, standard deviation (StDev), skewness and kurtosis of UTCI for (a) Cfb; (b) Cfc; (c) Dfb; (d) Dfc; (e) Dwb; (f) Dwc; (g) Dsc and (h) ET bio climate.

zone. Typically, slight cold stress occurred from April to June and in September. During the period, the lowest minimum and highest maximum UTCI were $-20.6^{\circ} \mathrm{C}$ and $14.9^{\circ} \mathrm{C}$, respectively (Table 2 ).

In both $\mathrm{Cfb}$ and $\mathrm{Cfc}$ bio-climates, spatial-inter-annual variability in thermal comfort levels was higher for the cold than warm thermal range. In $\mathrm{Cfb}$ bio-climate, spatial-inter-annual variance in UTCI-values was largest in February followed by November and March, and smallest in July. Spatial-inter-annual variability in monthly mean minimum UTCI, for instance, was more than twice as high as that of the monthly mean maximum UTCI. In Cfc climate, spatial- 
Table 2. Minimum $\overline{U T C I}_{K G C \min }$ and maximum $\overline{U T C I}_{K G C \max }$ universal thermal comfort indices, standard deviation, $\sigma$, skewness, and kurtosis calculated over all months and sites of available data for a respective bio-climate region as well as the minimum $U T C I_{\min }$ and maximum hourly universal thermal comfort index $U T C I_{\max }$ within the respective bioclimate region during the period. Here \# is the number of sites having hourly data for all months of at least one year. Only sites on land are considered.

\begin{tabular}{|c|c|c|c|c|c|c|c|c|c|}
\hline \multirow{2}{*}{ Quantity } & \multicolumn{9}{|c|}{ Bio-climate } \\
\hline & $\mathrm{Cfb}$ & $\mathrm{Cfc}$ & Dfb & Dfc & Dsc & Dwb & Dwc & EF & ET \\
\hline$\overline{U T C I}_{K G C \min }$ & -5.4 & -14.7 & -14.0 & -21.1 & -23.3 & -18.0 & -24.8 & -37.3 & -33.9 \\
\hline$\sigma\left(\overline{U T C I}_{K G C \min }\right)$ & 3.2 & 4.2 & 6.2 & 8.6 & 8.2 & 6.3 & 6.6 & 9.3 & 4.5 \\
\hline$\overline{\text { Skewness of }}_{\overline{U T C I}}{ }_{K G C \min }$ & -0.8 & -0.5 & -0.1 & 0.1 & 0.1 & 0.5 & 0.4 & 0.2 & 1.2 \\
\hline $\begin{array}{c}\text { Kurtosis of } \\
\left(\overline{U T C I}_{K G C \min }\right)\end{array}$ & -0.2 & -1.8 & -1.1 & -0.4 & -2.0 & -1.1 & -0.6 & -1.3 & 12.5 \\
\hline$U T C I_{K G C \min }$ & -12.8 & -20.6 & -28.5 & -40.6 & -31.7 & -27.3 & -37.9 & -45.6 & -40.0 \\
\hline$\overline{U T C I}_{K G C \max }$ & 16.3 & 11.0 & 18.6 & 15.9 & 16.6 & 20.6 & 14.9 & -4.5 & 2.6 \\
\hline$\sigma\left(\overline{U T C I}_{K G C \max }\right)$ & 1.5 & 2.7 & 4.5 & 5.0 & 5.9 & 5.8 & 5.1 & 16.3 & 4.0 \\
\hline$\overline{U T C I}_{\text {SkC max }}$ & -0.4 & 0.8 & 0.5 & -0.7 & -0.1 & -0.3 & 0.3 & -0.1 & 0.0 \\
\hline$\frac{\text { Kurtosis of }}{U T C I}_{K G C \max }$ & -1.4 & -1.7 & -0.1 & 0.2 & -1.8 & -1.1 & 0.3 & -2.3 & 0.7 \\
\hline$U T C I_{K G C \max }$ & 18.6 & 14.9 & 9.9 & 25.0 & 19.5 & 24.3 & 34 & 10.9 & 18.6 \\
\hline \# of sites & 14 & 4 & 26 & 111 & 5 & 11 & 114 & 7 & 62 \\
\hline
\end{tabular}

inter-annual variance was largest in January and smallest in September (cf. Figure 8(a), Figure $8(\mathrm{~b})$ ).

The pattern in inter-annual variability can be explained as follows: High UTCI values are associated with low cloudiness, high-pressure situations. Under such synoptic situations, shortwave radiation, calm winds and topography govern the temperature and moisture conditions over a large area [37] [49]. However, low UTCI values occur under cyclonic conditions. Wind speeds, cloudiness, humidity and temperatures strongly differ before and after a frontal passage. The resulting strong gradients in meteorological parameters over the bio-climate region yield great variability in UTCI.

\subsubsection{Humid Continental Climate (Dfb, Dwb)}

$\mathrm{Dfb}$ and Dwb climates are hemi-boreal [28]. Temperatures of the four warmest months are $10^{\circ} \mathrm{C}$ or above, but less than $22^{\circ} \mathrm{C}$. These bio-climates mainly differ by the timing of precipitation (not shown).

In the annual course, period-spatial highest and lowest mean monthly UTCI differed $32.5 \mathrm{~K}$ and $38.6 \mathrm{~K}$ in Dfb and Dwb climate, respectively. In Dfb climate, 
on period-spatial average, January and July had the lowest $\left(-14.0^{\circ} \mathrm{C}\right)$ and highest monthly mean UTCI $\left(18.6^{\circ} \mathrm{C}\right)$, respectively. Monthly mean UTCIs indicated at least moderate cold stress from November to March (Figure 8(c)). Lowest and highest UTCIs obtained at sites with Dfb climate were $-28.5^{\circ} \mathrm{C}$ and $9.9^{\circ} \mathrm{C}$ (Table

2) indicating strong and no thermal stress for the extremes, respectively.

In Dwb climate, on period-spatial average, January and July had the lowest $\left(-18.0^{\circ} \mathrm{C}\right.$; strong thermal stress) and highest monthly mean UTCIs $\left(20.6^{\circ} \mathrm{C}\right.$; no thermal stress). This wider range in UTCI values in Dwb than in Dfb bio-climate results from the enhanced humidity due to winter precipitation and less humidity in summer. In Dwb bio-climate, the lowest and highest UTCI were $-27.3^{\circ} \mathrm{C}$ (strong thermal stress) and $24.3^{\circ} \mathrm{C}$ (no thermal stress), respectively (Table 2). Monthly mean UTCI values indicated moderate or worse cold stress from October to March (Figure 8(e)).

In both Dfb and Dwb bio-climates, spatial-inter-annual variance in monthly mean UTCIs was lowest in September. In Dfc bio-climate, this variability was notably higher from November to March than in the other months, largest in December followed by November and February. In Dwb bio-climate, January saw the highest spatial-inter-annual variance followed by November and February. The strong decrease and increase of solar radiation with latitude (Figure 3) in these months are major reasons. In summer, latitudinal differences in solar radiation are much smaller over these regions.

\subsubsection{Continental Subarctic Climate (Dfc, Dwc)}

Dfc and Dwc climates are colder than Dfb and Dwb climates. Again, Dfc and Dwc climate are the same with respect to their temperature thresholds, but differ by the timing of precipitation.

The vicinity to the Canadian High leads to mostly calm or no wind conditions in Interior Alaska. In Dfc bio-climate, highest and lowest period-spatial monthly means of UTCI differed $35.9 \mathrm{~K}$. Typically, January and July had the lowest $\left(-20.6^{\circ} \mathrm{C}\right.$; strong cold stress) and highest monthly mean UTCIs $\left(15.3^{\circ} \mathrm{C}\right.$; no thermal stress), respectively. Averaged over the period and all Dfc sites, monthly mean UTCIs indicated various degrees of cold stress from October to April with at least moderate cold stress (Figure 8(d)). The lowest and highest UTCI obtained at sites with Dfc bio-climate were $-40.7^{\circ} \mathrm{C}$ (extreme cold stress) and $25.0^{\circ} \mathrm{C}$ (no thermal stress), respectively (Table 2 ).

Due to the high humidity associated with winter precipitation, highest and lowest period-spatial monthly mean UTCI differed $39.8 \mathrm{~K}$ in Dwc bio-climate. On period-spatial average, the lowest minimum $\left(-24.8^{\circ} \mathrm{C}\right)$ and highest maximum monthly mean UTCIs $\left(14.9^{\circ} \mathrm{C}\right)$ occurred in January and July, respectively. Monthly mean UTCIs were below $0^{\circ} \mathrm{C}$ from October to April (Figure 8(f)). The lowest and highest UTCIs calculated for sites with Dwc bio-climate were $-37.9^{\circ} \mathrm{C}$ and $34.3^{\circ} \mathrm{C}$, respectively (Table 2 ). This means both very strong cold stress and strong heat stress occurred.

Despite of the distinct different precipitation conditions in Dfc (highest preci- 
pitation amount in August; cf. Figure 6(c)) and Dwc (dry summer) bio-climate, August UTCIs showed the least variability in space and time. In Dfc bio-climate, highest spatial-inter-annual variance in thermal comfort conditions occurred in March followed by April (melting season), while in Dwc bio-climate, highest spatial-inter-annual variance occurred in April followed by March, May, and February.

\subsubsection{Mediterranean-Influenced Subarctic Climate (Dsc)}

At the few sites with Dsc bio-climate, highest and lowest period-spatial monthly mean UTCIs differed $39.9 \mathrm{~K}$. On period-spatial average, the minimum $\left(-23.3^{\circ} \mathrm{C}\right)$ and maximum monthly mean UTCIs $\left(16.6^{\circ} \mathrm{C}\right)$ occurred in January and July, respectively. Monthly mean UTCIs stayed below freezing from October to April (Figure $8(\mathrm{~g})$ ). The humidity and wind from the ocean caused moderate to strong cold stress during these months. During 1979-2017, the lowest and highest UTCI in Dsc climate were $-31.7^{\circ} \mathrm{C}$ (very strong cold stress) and $19.5^{\circ} \mathrm{C}$ (no thermal stress), respectively (Table 2). The high heat capacity of the ocean delays warm-up in spring and may result in cool sea-breezes keeping summers comfortable. In fall, the high heat capacity of the ocean contributes to mild conditions. The winds and high humidity yield cold stress of various degrees in winter and spring.

Spatial-inter-annual variance in UTCIs was highest in April caused by occasional late snowfall and the presence or absence of sea-ice close to the shores. During June to September spatial-inter-annual variance in thermal conditions was notably lower than during the cold season with September having the least variability. The strong inter-annual variability of thermal comfort in winter can be attributed to the inter-annual variability in storm tracks and extension/location of high-pressure systems. Storms from the south advect Mediterranean warm air masses, while a strong high-pressure system can advect Arctic cold air from the Interior and Yukon Territory.

\subsubsection{Tundra and Ice-Cap Climate (ET, EF)}

As can be seen in Figure 3, solar insolation gradually decreases northward over the tundra leading to no insolation from late November to end of January in the northernmost areas. During that time, long-wave radiation loss governs the energy budget and thermal comfort. Once the Sun comes back, the high albedo of snow reflects huge amounts of shortwave radiation that reaches the surface.

In ET bio-climate, monthly mean UTCI were above freezing only in July meaning still slight cold stress on average. Very strong cold stress with monthly mean UTCIs below $-30^{\circ} \mathrm{C}$ occurred from December to March.

In EF climate, the annual course of period-spatial monthly mean UTCI was asymmetric with only negative values (not shown). Various degrees of cold stress existed year round reaching very strong cold stress in January to March $\left(<-35^{\circ} \mathrm{C}\right)$. Monthly mean UTCIs showed a steep increase in April and peaked in June. Thereafter, monthly means of UTCI steadily decreased to $-28.6^{\circ} \mathrm{C}$ (strong cold stress) in December. 
In ET bio-climate, spatial-inter-annual variance in monthly mean UTCI was highest in March and lowest in August (Figure 8(h)). Skewness and kurtosis were highest in February when the Sun comes again above the horizon. Both skewness and kurtosis had a secondary maximum in November when the solar insolation reached zero (Figure 8(h), Figure 3).

In EF climate, spatial-inter-annual variance in monthly UTCIs was least in November to January, largest in June and marginally less in May. In the former months, long-wave radiation dominates, while in June shortwave radiation at the TOA is the largest (Figure 3 ). The high inter-annual variability results from variability in cloudiness and hence shortwave radiation reaching the surface. Skewness ranged between -0.3 (September) and 0.5 (February). Kurtosis was negative in all months with higher absolute values in summer than winter.

\subsection{Climatology of Alaska Thermal Comfort}

In this analysis, for each of the 456 sites, its total available data were taken as $100 \%$. Figure 9 shows for each of the sites the most often occurring thermal comfort level and the percentage of hours it occurred. No thermal stress existed between $20 \%$ and $30 \%$ of the time in the Interior of Alaska as well as $25 \%$ to $40 \%$ of the time in the Inside Passage. Along the Gulf of Alaska, slight and moderate cold stress dominated the thermal comfort levels. In the Aleutians, moderate and strong cold stress were the most frequent conditions governing the thermal comfort levels $15 \%$ to $35 \%$ of the time.

Crews on oil and gas platforms in the Chukchi and Beaufort Seas were exposed to very strong or strong cold stress $45 \%$ to $50 \%$ of the time (Figure 9 , Figure 10). Slight cold stress existed in the Chukchi and Beaufort Seas up to 20\%

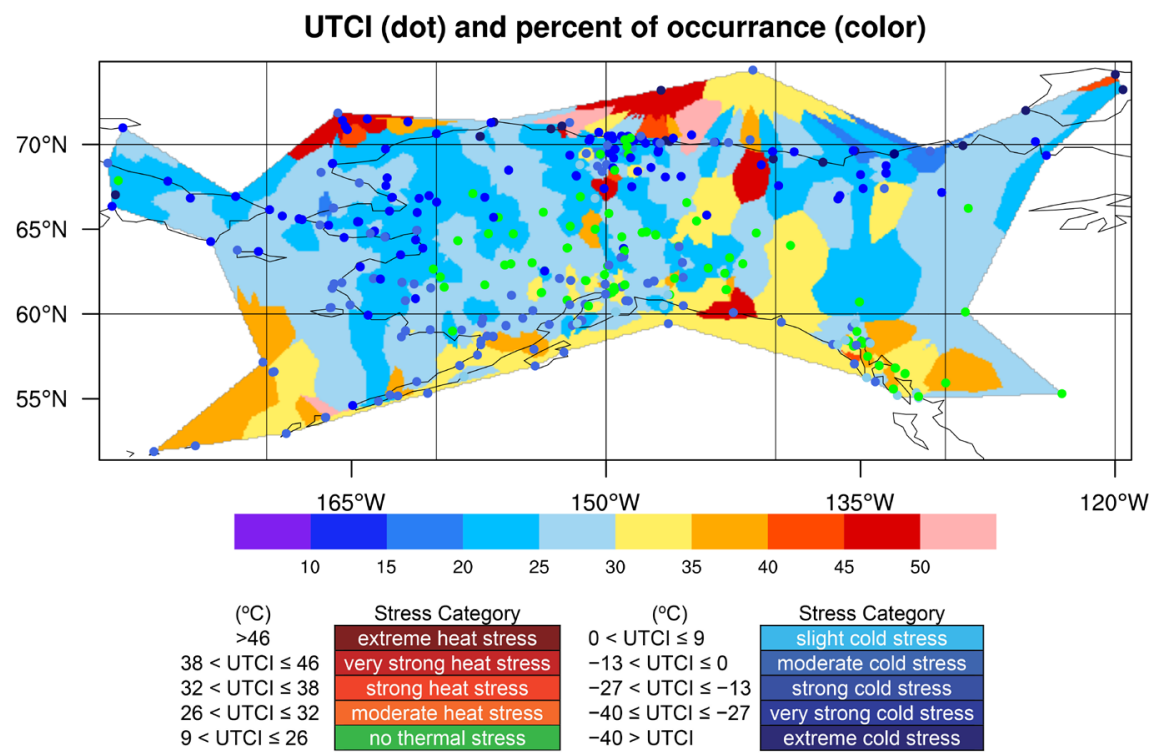

Figure 9. Map showing the most often occuring thermal comfort conditions at a site (color-coded dots) in Alaska and their percentage of occurrence between 1979 and 2017 (color shaded areas) interpolated between sites. Note the sites in Canada and Russia served in the interpolation for improved coverage of Alaska. 

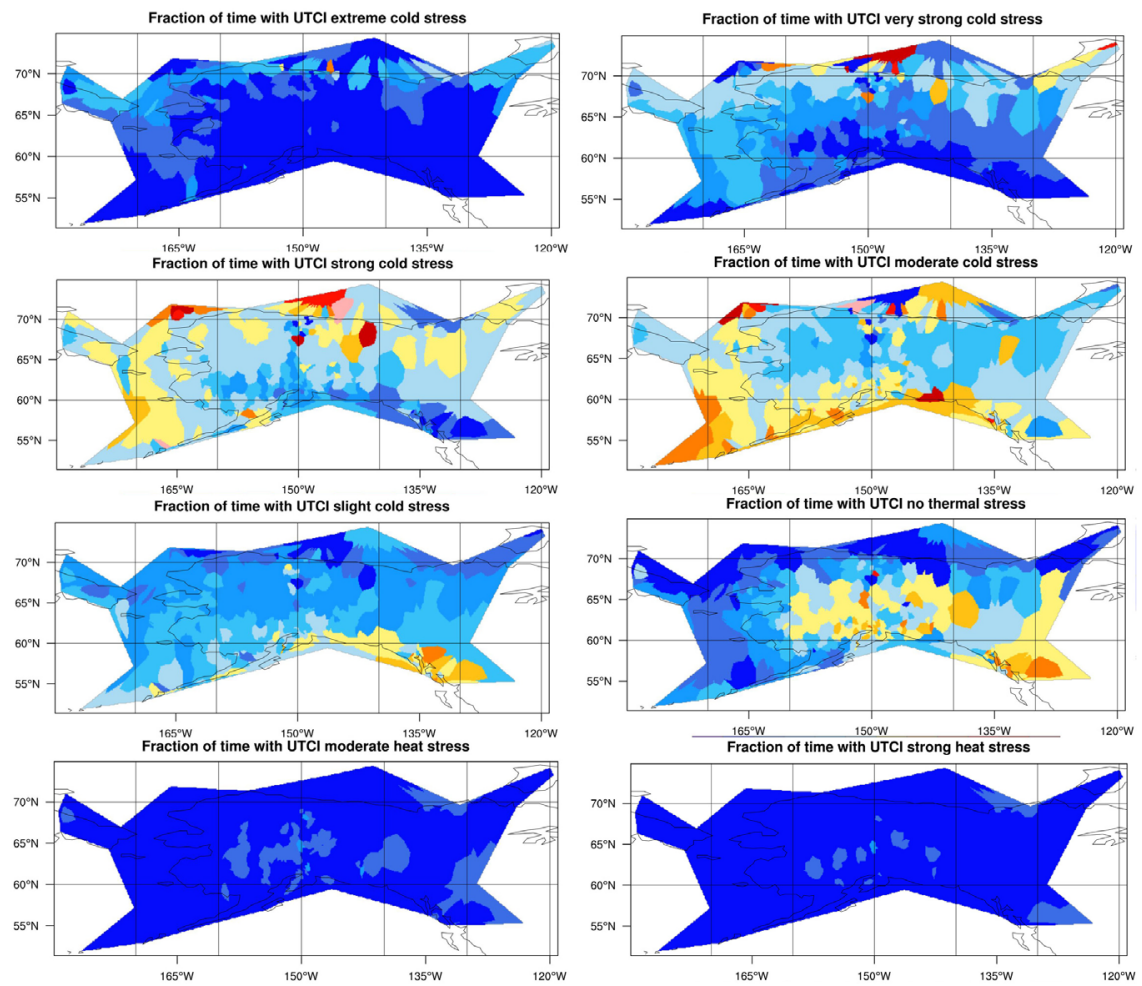

Time fraction (\%)

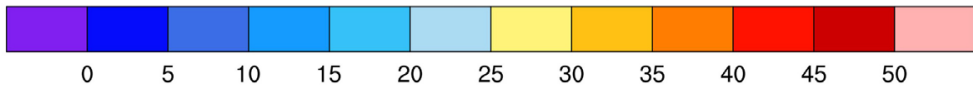

Figure 10. Interpolated maps of percent of occurrence of various thermal comfort conditions for Alaska. Strong and extreme heat stress occur less than $5 \%$ of the time in Alaska (therefore not shown).

of the time. In the eastern Beaufort Sea, moderate cold stress occurred up to $35 \%$ of the time (Figure 9). Note that ships cruise in these seas from June to late October [2] [50].

The continental regions of Alaska (and the Yukon Territory) had slight heat stress up to $10 \%$. In some places, strong heat stress occurred on occasions as well. The continental regions of Alaska experienced a higher fraction of time with very strong cold stress than those along the Gulf of Alaska or in the Aleutian (Figure 9). Along the Alaska West Coast, the fraction of time with very strong cold stress increased with latitude reaching up to $25 \%$ on the North Slope. This means the low or lack of insolation played a key role for deep winter thermal comfort. Note that pockets with even more hours of very strong cold stress occurred.

\section{Discussion, Conclusions and Outlook}

By using available near-surface meteorological data of 1979 to 2017 from 456 sites in Alaska, northwestern Canada and eastern Russia universal thermal comfort indices (UTCI) were modeled and interpolated in space to create the first high resolution thermal comfort climatology for Alaska. This climatology in- 
cludes maps of the percentage of time that the various thermal comfort levels occurred. Furthermore, it also includes the mean thermal comfort in Alaska's Köppen-Geiger bio-climates.

The 1979-2017 thermal climatology of Alaska reveals the following. At most sites and in all bio-climates in Alaska, thermal comfort levels encompassed a wider range than actual air temperatures. In general, differences between actual air temperature and UTCI varied with the time of the day, day and month of the year (i.e. shortwave radiation reaching the ground, long-wave radiation loss, wind speed, humidity). The various bio-climates differed in the range of thermal comfort levels as well as timing of when monthly means of air temperatures exceeded those of UTCI and vice versa. However, at most sites, monthly mean UTCI values exceeded monthly mean air temperatures in summer, while the opposite was true in winter. Typically, monthly means of daily minimum UTCI were lower than monthly means of daily minimum air temperature; the opposite was true for the maxima.

The thermal conditions with the highest percentage of occurrence ranged from slight cold stress to very strong cold stress except for Interior Alaska and along the Inside Passage. In Interior Alaska and along the Inside Passage, no thermal stress had the highest percentage of occurrence. Nevertheless, cold stress of different degrees dominated overall in these two regions. These two regions and the very continental Dwc bio-climate had the widest range of thermal conditions. However, in the former two regions, thermal comfort levels reached from extreme cold to very strong heat stress, while they reached from very strong cold stress to strong heat stress in Dwc bio-climate. However, the frequency of occurrence was marginal for these extremes in all three regions.

Along the coasts of West and North Alaska and the northern Gulf of Alaska some degrees of cold stress had the largest percentage of occurrence. Along the northern Gulf of Alaska, wind and enhanced humidity from the ocean were notable contributors to low UTCI levels. Along the Bering Sea coast north of the Arctic Circle and along the coast of the Arctic Ocean, the low or lack of solar insolation in combination with long-wave radiation loss in winter and windy, humid conditions in summer led to on average uncomfortable thermal conditions year round.

Except for Dwc climate, spatial-inter-annual variability in thermal comfort levels was higher for the cold than warm thermal range, but differed in timing of minima and maxima among bio-climates. In Dwc bio-climate, spatial-inter-annual variability in UTCI was larger in the first than second half of the year.

In ET climate, the skewness and kurtosis of UTCI increased strongly in February and November due to the incremental northward increase and decrease, respectively, of shortwave radiation reaching the surface. In all other bio-climates, skewness and kurtosis showed only marginal differences among months.

While the UTCI was developed to be applicable universally to different climates, a human behavior is the thermal adaptation to their own bio-climate [51]. Their past experiences and culture may influence their expectations and percep- 
tions of thermal-environmental conditions, and effector behavior. Studies comparing the clothing behavior of residents with similar summer UTCI-ranges showed that those living in Melbourne wore more clothing $(0.1$ clo) than those in Hong Kong [52]. This means that the Alaska thermal comfort climatology might underestimate the thermal stress of new residents and tourists.

In the regions of increased exploration, oil and gas production, strong to very strong cold stress dominated. Thermal comfort rarely exceeded slight cold stress. Similar was true for the regions of increased shipping. Based on these findings one may conclude that here the capacities for treatment of cold stress related symptoms have to be extended as the population, ship and air traffic increases on the North Slope and its coastal waters. The increasing tourism for aurora watching, dog-mushing, hiking, kayaking, fishing, boating etc. in Interior Alaska will require expansion of capacity to treat patients with cold and heat thermal stress.

The more than 23\% growth in Alaska's population mainly increased the outskirts of the three major cities (Anchorage, Fairbanks, Juneau). Recent studies showed that increasing urbanization and improved urban planning, among other things, altered the thermal stress in European cities of different background climates over time [53]. Given the few urban sites in Alaska, of which many have only short time series, the assessment of small-scale differences in thermal comfort and planning for its improvement remain a challenge. Thus, the development of urban thermal comfort models is an urgent need as well.

Major challenges in determining a thermal comfort climatology for Alaska were the quantity and quality of available data. While at a few sites, over 100 years of data exist [29], the number of available sites and the spatial resolution of sites were too coarse for a meaning-full spatial climatology starting at that time. Furthermore, some of these early time series only reported daily maxima, minima and means, i.e. they had a coarse temporal resolution. Thus, using the data from 1979 to 2017 was a compromise between sufficient spatial resolution, number of sites and length of the time series.

However, when looking at a limited timeframe, extreme events with low probability of occurrence may be missed. For instance, the highest and lowest recorded temperature since onset of recording were $37.8^{\circ} \mathrm{C}$ (Ft. Yukon, June 27 1915) and $-62.2^{\circ} \mathrm{C}$ (Prospector Creek, January 23, 1971), respectively [29]. This means that the 1979-2017 sample missed these and probably other local extremes.

The investigations of thermal comfort at different temporal scales revealed that a climatology based on coarse temporal resolution data would exclude hourly or daily extremes. This means that in assessment of future thermal comfort conditions, thermal indices will have to be determined within the simulation of the climate projection itself. Using, for instance, output data of climate-model projections with $3 \mathrm{~h}$ or $6 \mathrm{~h}$ or even longer time increments may underestimate the severity and frequency of hazardous thermal situations. 


\section{Acknowledgements}

I thank G. Kramm and the anonymous reviewers for fruitful comments and discussion. My thanks also go to the many PIs and their co-workers of the various research projects that made their data available in the data archives used in this study. Data stem from the National Centers for Environmental Information (NCEI), National Climatic Data Center (NCDC), United States Geological Survey (USGS), Atmospheric Radiation Measurements (ARM), Water Engineering Research Center (WERC), Bureau of Ocean Energy Management (BOEM) and Western Region Climate Center (WRCC). The model to calculate UTCI stems from P. Bröde. Financial support came from the State of Alaska.

\section{Conflicts of Interest}

The author declares no conflicts of interest regarding the publication of this paper.

\section{References}

[1] US Census Bureau (2019) 2018 National Population Projections.

[2] Arctic-Council (2009) Arctic Marine Shipping Assessment 2009 Report. 194 p.

[3] Mölders, N. and Gende, S. (2016) On the Limits to Manage Air-Quality in Glacier Bay. Journal of Environmental Protection, 7, 1923-1955. https://doi.org/10.4236/jep.2016.712151

[4] Laschewski, G. and Jendritzky, G. (2002) Effects of the Thermal Environment on Human Health: An Investigation of 30 Years of Daily Mortality Data from SW Germany. Climate Research, 21, 91-103. https://doi.org/10.3354/cr021091

[5] Mercer, J.B. (2003) Cold-An Underrated Risk Factor for Health. Environmental Research, 92, 8-13. https://doi.org/10.1016/S0013-9351(02)00009-9

[6] Kysely, J., Pokorna, L., Kyncl, J. and Kriz, B. (2009) Excess Cardiovascular Mortality Associated with Cold Spells in the Czech Republic. BMC Public Health, 9, 19. https://doi.org/10.1186/1471-2458-9-19

[7] Ma, W., Yang, C., Chu, C., Li, T., Tan, J. and Kan, H. (2013) The Impact of the 2008 Cold Spell on Mortality in Shanghai, China. International Journal of Biometeorology, 57, 179-184. https://doi.org/10.1007/s00484-012-0545-7

[8] Di Napoli, C., Pappenberger, F. and Cloke, H.L. (2018) Assessing Heat-Related Health Risk in Europe via the Universal Thermal Climate Index (UTCI). International Journal of Biometeorology, 62, 1155-1165. https://doi.org/10.1007/s00484-018-1518-2

[9] Skutecki, R., Jalali, R., Dragańska, E., Cymes, I., Romaszko, J. and Glińska-Lewczuk, K. (2019) UTCI as a Bio-Meteorological Tool in the Assessment of Cold-Induced Stress as a Risk Factor for Hypertension. Science of the Total Environment, 688, 970-975. https://doi.org/10.1016/j.scitotenv.2019.06.280

[10] Blazejczyk, K., Epstein, Y., Jendritzky, G., Staiger, H. and Tinz, B. (2012) Comparison of UTCI to Selected Thermal Indices. International Journal of Biometeorology, 56, 515-535. https://doi.org/10.1007/s00484-011-0453-2

[11] Krüger, E.L., Minella, F.O. and Matzarakis, A. (2014) Comparison of Different Methods of Estimating the Mean Radiant Temperature in Outdoor Thermal Comfort Studies. International Journal of Biometeorology, 58, 1727-1737. 
https://doi.org/10.1007/s00484-013-0777-1

[12] Buzan, J.R., Oleson, K. and Huber, M. (2015) Implementation and Comparison of a Suite of Heat Stress Metrics within the Community Land Model Version 4.5. Geoscientific Model Development, 8, 151-170. https://doi.org/10.5194/gmd-8-151-2015

[13] Zare, S., Hasheminejad, N., Shirvan, H.E., Hemmatjo, R., Sarebanzadeh, K. and Ahmadi, S. (2018) Comparing Universal Thermal Climate Index (UTCI) with Selected Thermal Indices/Environmental Parameters During 12 Months of the Year. Weather and Climate Extremes, 19, 49-57. https://doi.org/10.1016/j.wace.2018.01.004

[14] Houghton, F.C. and Yaglou, C.P. (1923) Determining Equal Comfort Lines. J. Am. Soc. Heating and Ventilation in England, 29, 165-176.

[15] Fountain, M. and Huizenga, C. (1995) A Thermal Sensation Model for Use by the Engineering Profession-Results of Cooperative Research between the American Society of Heating, Refrigeration, and Air-Conditioning Engineers, Inc. and Environmental Analytics. 1-55.

[16] Salata, F., Golasi, I., De Lieto Vollaro, R. and De Lieto Vollaro, A. (2016) Outdoor Thermal Comfort in the Mediterranean Area. A Transversal Study in Rome, Italy. Building and Environment, 96, 46-61. https://doi.org/10.1016/j.buildenv.2015.11.023

[17] Jendritzky, G. and Nubler, W. (1981) A Model Analyzing the Urban Thermal Environment in Physiologically Significant Terms. Archives of Meteorology and Geophysical Bioclimatology, 29, 313-326. https://doi.org/10.1007/BF02263308

[18] Pickup, J. and De Dear, R. (2000) An Outdoor Thermal Comfort Index (OUTSET $^{\star}$ )-Part I-The Model and Its Assumptions. 5 th International Congress of Biometeorology and International Conference on Urban Climatology, Macquarie University, Sydney, 279-283.

[19] ASHRAE (2001) ASHRAE Fundamentals Handbook 2001. SI Edition. 892 p.

[20] Thorsson, S., Lindqvist, M. and Lindqvist, S. (2004) Thermal Bioclimatic Conditions and Patterns of Behaviour in an Urban Park in Göteborg, Sweden. International Journal of Biometeorology, 48, 149-156. https://doi.org/10.1007/s00484-003-0189-8

[21] Golasi, I., Salata, F., De Lieto Vollaro, E. and Coppi, M. (2018) Complying with the Demand of Standardization in Outdoor Thermal Comfort: A First Approach to the Global Outdoor Comfort Index (GOCI). Building and Environment, 130, 104-119. https://doi.org/10.1016/j.buildenv.2017.12.021

[22] Lindberg, F., Holmer, B., Thorsson, S. and Rayner, D. (2013) Characteristics of the Mean Radiant Temperature in High Latitude Cities-Implications for Sensitive Climate Planning Applications. International Journal of Biometeorology, 58, 613-627. https://doi.org/10.1007/s00484-013-0638-y

[23] Gommershtadt, O., Konstantinov, P., Varentsov, M. and Baklanov, A. (2020) Modeling Technology for Assessment of Summer Thermal Comfort Conditions of Arctic City on Microscale: Application for City of Apatity. In: Vasenev, V., Dovletyarova, E., Cheng, Z., Valentini, R. and Calfapietra, C., Eds., Green Technologies and Infrastructure to Enhance Urban Ecosystem Services. SSC 2018, Springer Geography, Springer, Cham, 66-75. https://doi.org/10.1007/978-3-030-16091-3_10

[24] Kottek, M., Grieser, J., Beck, C., Rudolf, B. and Rubel, F. (2006) World Map of the Köppen-Geiger Climate Classification Updated. Meteorologische Zeitschrift, 15, 259-263. https://doi.org/10.1127/0941-2948/2006/0130

[25] Harris, I., Jones, P.D., Osborn, T.J. and Lister, D.H. (2013) Updated High-Resolution 
Grids of Monthly Climatic Observations-The CRU TS3.10 Dataset. International Journal of Climatology, 34, 623-642. https://doi.org/10.1002/joc.3711

[26] Schneider, U., Fuchs, T., Meyer-Christoffer, A. and Rudolf, B. (2008) Global Precipitation Analysis Products of the GPCC. Global Precipitation Climatology Centre (GPCC), Deutscher Wetterdienst, Offenbach, Germany, 12 p.

[27] Mölders, N. and Kramm, G. (2018) Climatology of Air Quality in Arctic Cities-Inventory and Assessment. Open Journal of Air Pollution, 7, 48-93. https://doi.org/10.4236/ojap.2018.71004

[28] Geiger, R. (1961) Überarbeitete Neuausgabe Von Geiger, R. Köppen Geiger/Klima der Erde. (Wandkarte 1:16 Mill.).

[29] Shulski, M. and Wendler, G. (2007) The Climate of Alaska. 216 p.

[30] Bieniek, P.A., Walsh, J.E., Thoman, R.L. and Bhatt, U.S. (2014) Using Climate Divisions to Analyze Variations and Trends in Alaska Temperature and Precipitation. Journal of Climate, 27, 2800-2818. https://doi.org/10.1175/JCLI-D-13-00342.1

[31] Pappenberger, F., Jendritzky, G., Staiger, H., Dutra, E., Di Giuseppe, F., Richardson, D.S. and Cloke, H.L. (2015) Global Forecasting of Thermal Health Hazards: The Skill of Probabilistic Predictions of the Universal Thermal Climate Index (UTCI). International Journal of Biometeorology, 59, 311-323. https://doi.org/10.1007/s00484-014-0843-3

[32] Jendritzky, G., Bröde, P., Fiala, D., Habvenith, G., Weihs, P., Batchvarova, E. and Dedear, R. (2009) Der Thermische Klimaindex UTCI. 96-101.

[33] Bröde, P., Fiala, D., Błażejczyk, K., Holmér, I., Jendritzky, G., Kampmann, B., Tinz, B. and Havenith, G. (2012) Deriving the Operational Procedure for the Universal Thermal Climate Index (UTCI). International Journal of Biometeorology, 56, 481494. https://doi.org/10.1007/s00484-011-0454-1

[34] Psikuta, A., Fiala, D., Laschewski, G., Jendritzky, G., Richards, M., Błażejczyk, K., Mekjavič, I., Rintamäki, H., De Dear, R. and Havenith, G. (2012) Validation of the Fiala Multi-Node Thermophysiological Model for UTCI Application. International Journal of Biometeorology, 56, 443-460. https://doi.org/10.1007/s00484-011-0450-5

[35] Fiala, D., Havenith, G., Bröde, P., Kampmann, B. and Jendritzky, G. (2012) UTCIFiala Multi-Node Model of Human Heat Transfer and Temperature Regulation. International Journal of Biometeorology, 56, 429-441. https://doi.org/10.1007/s00484-011-0424-7

[36] Havenith, G., Fiala, D., Błazejczyk, K., Richards, M., Bröde, P., Holmér, I., Rintamaki, H., Benshabat, Y. and Jendritzky, G. (2012) The UTCI-Clothing Model. International Journal of Biometeorology, 56, 461-470. https://doi.org/10.1007/s00484-011-0451-4

[37] Mölders, N. and Kramm, G. (2014) Lectures in Meteorology. Springer Nature, Switzerland, 591 p. https://doi.org/10.1007/978-3-319-02144-7

[38] Baldasano, J.M., Valera, E. and Jiménez, P. (2003) Air Quality Data from Large Cities. The Science of the Total Environment, 307, 141-165. https://doi.org/10.1016/S0048-9697(02)00537-5

[39] Sundqvist, H., Berge, E. and Kristjánsson, J.E. (1989) Condensation and Cloud Parameterization Studies with a Mesoscale Numerical Weather Prediction Model. Monthly Weather Review, 117, 1641-1657. https://doi.org/10.1175/1520-0493(1989)117<1641:CACPSW>2.0.CO;2

[40] Sormunen, E. (2009) Repetitive Work in the Cold-Work Ability, Musculoskeletal Symptoms and Thermal and Neuromuscular Responses in Food Industry Workers. 
University of Oulu, Oulu.

[41] Pantavou, K.G., Lykoudis, S.P. and Nikolopoulos, G.K. (2016) Milder Form of Heat-Related Symptoms and Thermal Sensation: A Study in a Mediterranean Climate. International Journal of Biometeorology, 60, 917-929. https://doi.org/10.1007/s00484-015-1085-8

[42] Oke, T.R. (1995) Boundary Layer Climates. Routledge, 464 p.

[43] Huang, J., Cedeño-Laurent, J.G. and Spengler, J.D. (2014) Citycomfort+: A Simulation-Based Method for Predicting Mean Radiant Temperature in Dense Urban Areas. Building and Environment, 80, 84-95. https://doi.org/10.1016/j.buildenv.2014.05.019

[44] Dimiceli, V.E., Piltz, S.F. and Amburn, S.A. (2013) Black Globe Temperature Estimate for the WBTG Index. In: Kim, H., Ao, S.I. and Rieger, B., Eds., IAENG Transactions on Engineering Technologies. Lecture Notes in Electrical Engineering, Springer, Dordrecht, 323-334. https://doi.org/10.1007/978-94-007-4786-9_26

[45] Köppen, W. (1900) Versuch Einer Klassifikation der Klimate, Vorzugsweise Nach Ihren Beziehungen Zur Pflanzenwelt. Geographische Zeitschrift, 6, 657-679.

[46] Von Storch, H. and Zwiers, F.W. (1999) Statistical Analysis in Climate Research. Cambridge University Press, Cambridge, 484 p. https://doi.org/10.1017/CBO9780511612336

[47] Gong, S.L., Zhao, T.L., Sharma, S., Toom-Sauntry, D., Lavoué, D., Zhang, X.B., Leaitch, W.R. and Barrie, L.A. (2010) Identification of Trends and Interannual Variability of Sulfate and Black Carbon in the Canadian High Arctic: 1981-2007. Journal of Geophysical Research: Atmospheres, 115. https://doi.org/10.1029/2009JD012943

[48] Kim, J., Waliser, D.E., Mattmann, C.A., Mearns, L.O., Goodale, C.E., Hart, A.F., Crichton, D.J., Mcginnis, S., Lee, H., Loikith, P.C. and Boustani, M. (2013) Evaluation of the Surface Climatology over the Conterminous United States in the North American Regional Climate Change Assessment Program Hindcast Experiment Using a Regional Climate Model Evaluation System. Journal of Climate, 26, 56985715. https://doi.org/10.1175/JCLI-D-12-00452.1

[49] Mölders, N. (2011) Land-Use and Land-Cover Changes: Impact on Climate and Air Quality. Springer Nature, Switzerland, 193 p. https://doi.org/10.1007/978-94-007-1527-1

[50] Winther, M., Christensen, J.H., Plejdrup, M.S., Ravn, E.S., Eriksson, Ó.F. and Kristensen, H.O. (2014) Emission Inventories for Ships in the Arctic Based on Satellite Sampled AIS Data. Atmospheric Environment, 91, 1-14. https://doi.org/10.1016/j.atmosenv.2014.03.006

[51] Lam, C.K.C. and Lau, K.K. (2018) Effect of Long-Term Acclimatization on Summer Thermal Comfort in Outdoor Spaces: A Comparative Study between Melbourne and Hong Kong. International Journal of Biometeorology, 62, 1311-1324. https://doi.org/10.1007/s00484-018-1535-1

[52] Matzarakis, A., Fröhlich, D., Bermon, S. and Adami, P. (2018) Quantifying Thermal Stress for Sport Events-The Case of the Olympic Games 2020 in Tokyo. Atmosphere, 9, 479. https://doi.org/10.3390/atmos9120479

[53] Founda, D., Pierros, F., Katavoutas, G. and Keramitsoglou, I. (2019) Observed Trends in Thermal Stress at European Cities with Different Background Climates. Atmosphere, 10, 436. https://doi.org/10.3390/atmos10080436 